\title{
Migraine variability: An underrecognized impediment to effective treatment
}

\author{
John Edmeads MD, Andrew Grenville PhD, Michel Aubé MD
}

\author{
J Edmeads, A Grenville, M Aubé. \\ Migraine variability: An underrecognized impediment to \\ effective treatment. \\ Pain Res Manage 1996;1(4):215-218.
}

OBJECTIVE: To determine whether individuals in a populationbased sample of migraine sufferers experience attacks that vary in intensity and in degree of disability, and to correlate any variability with age, sex, attack frequency and physician-consulting behaviour.

DESIGN: Telephone interviews of randomly selected, population-based sample.

PARTICIPANTS: Men and women, aged 15 years and older, with headaches conforming to modified International Headache Society diagnostic criteria for migraine.

METHODS: Sample selected by modified random digit dialling method, with call-backs. A total of 20,565 calls identified 341 migraine sufferers who were interviewed by trained interviewers from a survey research organization using a computer-assisted system.

DATA ANALYSIS: Descriptive, with differences between proportions of groups tested by $\chi^{2}$.

RESULTS: Eighty-nine per cent of all migraine suffers had experienced two or three levels of severity in their migraine attacks as assessed by debilitation.

CONCLUSIONS: Most migraine sufferers experience frequent variation in attack severity, a finding that has implications for the prescribing of appropriate treatment.

Key Words: Analgesics, Ergotamine, Migraine, Sumatriptan, Treatment, Variability

\section{Variabilité de la migraine : un obstacle insuffisamment reconnu nuisant à l'efficacité du traitement}

OBJECTIF : Déterminer si dans un échantillon de population donnée les individus souffrant de migraine ont des attaques dont les degrés d'intensité et d'incapacité varient et corréler toute variabilité avec l'âge, le sexe, la fréquence des attaques et le comportement des patients relativement aux consultations médicales.

MODÈLE : Interview téléphonique d'un échantillon de population donnée, choisi au hasard.

PARTICIPANTS : Hommes et femmes, de 15 ans et plus, souffrant de maux de tête selon le critère diagnostic modifié pour la migraine provenant de l'International Headache Society.

MÉTHODES : Échantillon choisi par la méthode modifiée de la composition aléatoire, avec second appel téléphonique. Un total de 20565 appels ont identifié 341 personnes souffrant de migraine qui ont été interviewées par des intervieweurs spécialisés d'un organisme de recherches par sondages utilisant un système assisté par ordinateur.

ANALYSE DES DONNÉES : Descriptive, avec des différences entre les proportions des groupes testées par la méthode du $\mathrm{Chi}^{2}$.

RÉSULTATS : Quatre-vingt-neuf pour cent de toutes les personnes souffrant de migraine avaient distingué deux ou trois niveaux de sévérité dans leurs accès migraineux estimés d'après le degré d'incapacité.

CONCLUSIONS : La sévérité des attaques varient fréquemment chez la plupart des personnes qui souffrent de migraine, un résultat qui a des implications pour la prescription d'un traitement approprié.

Sunnybrook Health Science Centre, North York, Ontario; Angus Reid Group, Toronto, Ontario; Montreal Neurological Institute and Hospital, McGill University, Montreal, Quebec

Correspondence and reprints: Dr J Edmeads, Physician-in-Chief, Sunnybrook Health Science Centre, Room D 474, Division of Neurology, University of Toronto, 2075 Bayview Avenue, North York, Ontario M4N 3M5. Telephone 416-480-4592, fax 416-480-6191

Accepted for publication October 3, 1996 
$T^{1}$ he International Headache Society (IHS) classification catalogues a multitude of headache types, including seven varieties of migraine (1). Population-based studies of headache prevalence have shown that some people experience both migraine headaches and tension-type headaches $(2,3)$. This intrapatient variability in headache type is important in selecting treatment because the effectiveness of different therapies varies by headache type (4).

Not as widely appreciated is that, within one headache type a patient may experience considerable variation from attack to attack, in terms of intensity, duration and disability. This has implications for treatment (5). Unaware that a patient has mild as well as severe migraine headaches, the physician may prescribe only a specific antimigraine medication such as ergotamine or sumatriptan to be taken for all attacks; this results in the inappropriate consumption of these expensive and powerful agents for mild headaches that could be handled with simpler analgesics. The reverse error has potentially more serious repercussions; failure to recognize that a patient is having some occasional severe headaches as well as more habitual milder headaches may lead a physician to prescribe only analgesics for all attacks, which can cause unsatisfactory pain relief, increasing consumption of analgesics in the attempt to obtain relief and the subsequent development of analgesic rebound headaches.

Why is the concept of migraine variability almost unknown to so many practitioners? One reason is that there is very little in the medical literature about it. A search of MEDLINE using the key words "variability", "migraine frequency" and "migraine severity" failed to identify any studies that addressed the issue of intrapatient variability.

Population-based research on headache sufferers has generally failed to consider the potential for intrapatient variability in migraine attacks. However, the type of questions used in most studies seem, tacitly, to acknowledge variability. For example, Stewart et al (6) recently reviewed 13 population-based studies that assessed migraine- and headache-related disability and noted that "with one exception, all studies report disability in relation to either usual headache in the previous year or as a composite of the disability from attacks in the past year" (emphasis added).

Goadsby (7) described migraine as a 'sensory storm' within the nervous system. This analogy is apt. No two storms are identical - some merely rumble; others wreak havoc. So it is with migraine. Given the potential therapeutic importance of intrapatient variability in migraine, and that it is underinvestigated, we undertook a preliminary exploration of this topic. Our objective was to determine whether a population-based sample of migraine sufferers experiences attacks that vary in the degree of disability they produce. While most physicians experienced in headache know this to be so, we wished to establish this objectively through epidemiological methods. We also looked for relationships between variation in migraine-related disability and age, sex, migraine frequency and physician-consulting behaviour.

\section{PATIENTS AND METHODS}

A modified random digit dialling method was used to select a population-based sample of men and women aged 15 years and older. Telephone numbers were produced using active Canadian three-digit prefix codes and random computer-generation of the last four digits. This method ensured that all numbers, listed and unlisted, had an equal chance of being selected. Persons answering the telephone were screened to ensure that they were at least 15 years old and were asked whether anyone in the household suffered from severe headaches. If there was more than one severe headache sufferer, the one who was available was interviewed. For each telephone number selected, an initial call and up to four call-backs were made. A total of 20,565 calls were made to identify a sample of 341 migraine sufferers (Figure 1).

Interviews were conducted between September 13 and October 14, 1994. Trained interviewers from the Angus Reid Group, a survey research organization, conducted the interviews using a computerassisted telephone interview system. Interviews in Quebec were conducted by bilingual interviewers in the respondent's choice of French or English. Interviews in the other provinces were conducted in English, unless the respondent specifically requested that the interview be in French. Approximately $10 \%$ of interviews were monitored or otherwise verified.

The major descriptive characteristics of migraine headaches were distilled from the IHS classification (1) categories 1.1 and 1.2, and rephrased in layman's language. These characteristics were used to aid in the identification of migraine sufferers. Respondents were

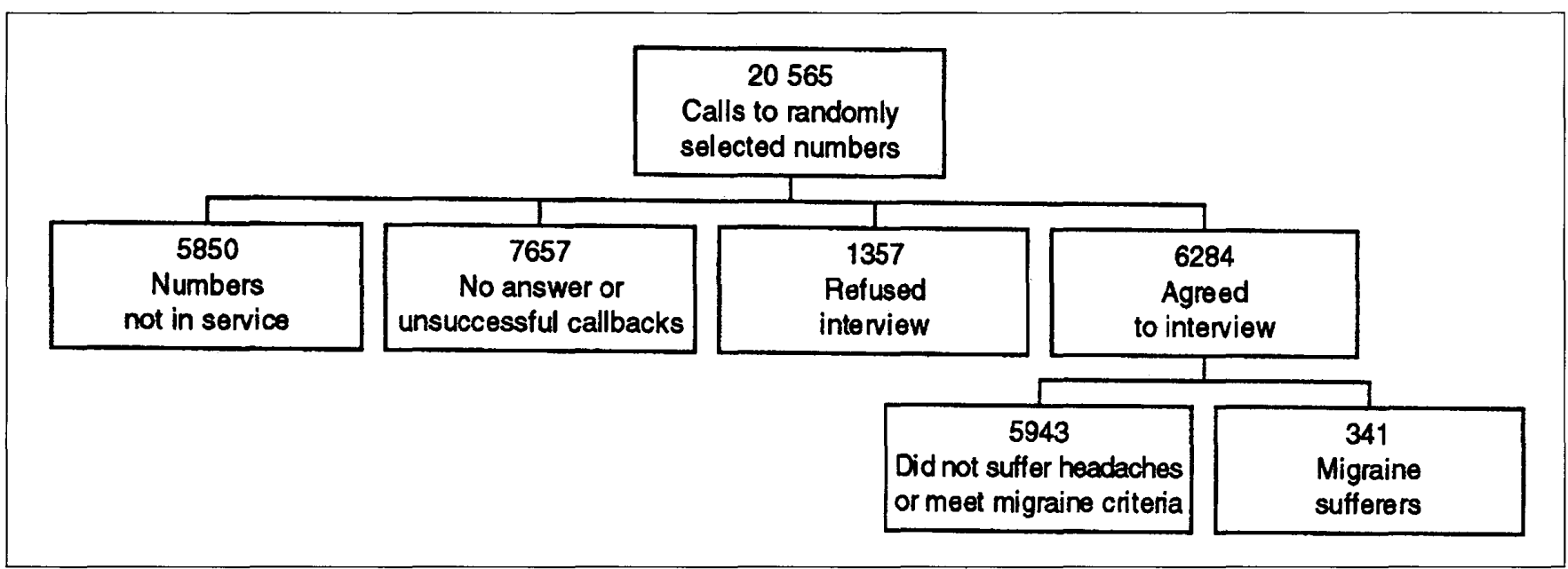

Figure 1) Flow chart of telephone calls 
asked to answer yes or no to the question, "Thinking of your most severe headaches, do you ever experience [individual items from a list of pain and associated symptoms]?". The four pain symptoms were as follows: pain that is severe enough to make it difficult or impossible to get through your normal day; pain on only one side (left or right) of your head; pain that is pulsating (like your heart beat) or throbbing; and pain that gets worse if you move around (at all). The two associated symptoms were pain so severe you cannot stand light or sound; and feeling sick or being sick with the headache. Respondents were considered to suffer migraine if they said yes to at least two of the pain symptoms, and to one or both of the questions regarding associated symptoms.

Those who met these criteria were further screened to determine whether they had been diagnosed as having migraine or felt that they suffered from migraine. This restriction was imposed because some questions required respondents to be aware that they experienced migraine attacks.

Those who met these criteria were then asked, "How many times have you had migraines in the past year?" Those who had experienced fewer than three attacks were excluded from the study because it was felt that they had migraine too infrequently to provide reliable information on variation in attack severity.

The final inclusion criterion was debilitation. The question used was, "How have migraines most often affected your ability to carry out your normal daily activities during attacks? Would you say that your activities are most often severely limited, that is, requiring bed rest; moderately limited, that is, unable to continue your normal daily activities, but not having to go to bed; limited somewhat, that is, able to continue your normal activities, but at a reduced capacity; or did not affect you at all?" Those who said their migraines did not at all affect their ability to function were excluded for not meeting IHS criteria. Information was also collected on sex, consulting behaviour (with physicians), medication use and age. Age in years was recorded using the following categories: 15 to $24 ; 25$ to 34 ; 35 to $44 ; 45$ to 54 ; and 55 or older. Attack frequency per year was categorized as three to $12 ; 13$ to 52 ; and 53 or more.

Questions about degree of disability were used as the measure of variability. Stewart and colleagues (6) concluded that "disability is particularly important because it is a direct measure of life impact and a direct consequence of other headache features, including pain intensity, attack duration, and a number of migrainous symptoms".

Differences between proportions of groups were tested for statistical significance using $\chi^{2}$; a $\mathrm{P}$ value of less than 0.05 was accepted as the marker of statistical significance.

\section{RESULTS}

The migraine sufferers identified using this methodology were similar demographically and symptomatically to those identified by a Canadian headache prevalence study that used similar diagnostic criteria (2).

Regarding the severity as assessed by disability, $89 \%$ of the respondents had experienced two or more severity levels of migraine attacks (Table 1). The percentage of those who had ever experienced each level of debilitation, as well as the specific combinations of severity types, is shown in Table 2 .

Since the peak age of migraine onset is relatively young (8), it
TABLE 1

Percentage of sufferers who ever experienced migraine attacks of one, two or three degrees of debilitation

\begin{tabular}{lc}
\hline $\begin{array}{l}\text { Number of degrees of debilitation } \\
\text { ever experienced }\end{array}$ & $\begin{array}{c}\text { \% of sufferers ever } \\
\text { experienced (n) }\end{array}$ \\
\hline Three & $58 \%(196)$ \\
Two only & $31 \%(104)$ \\
One only & $12 \%(41)$ \\
\hline
\end{tabular}

TABLE 2

Percentage of sufferers who ever experienced migraine attacks of each degree of debilitation and the percentage who ever experienced each combination of migraine attacks

\begin{tabular}{lc}
\hline $\begin{array}{l}\text { Degrees of debilitation ever } \\
\text { suffered with migraine attacks }\end{array}$ & $\begin{array}{c}\text { \% of sufferers ever } \\
\text { experienced (n) }\end{array}$ \\
\hline Severely debilitating & $82 \%(281)$ \\
Moderately debilitating & $81 \%(276)$ \\
Somewhat debilitating & $82 \%(280)$ \\
& \\
Combinations of degrees & \\
of debilitation & $\%$ of sufferers (n) \\
\hline Severe + moderate + somewhat & $58 \%(196)$ \\
Severe + moderate & $11 \%(39)$ \\
Severe + somewhat & $8 \%(27)$ \\
Moderate + somewhat & $11 \%(38)$ \\
Severe only & $6 \%(19)$ \\
Moderate only & $1 \%(3)$ \\
Somewhat only & $6 \%(19)$ \\
\hline
\end{tabular}

may be hypothesized that older migraine sufferers have had a greater number of migraine attacks and therefore have greater opportunity to experience attacks of different levels of debilitation. However, analysis of patients' ages and the number of types of attacks ever experienced revealed no significant differences between groups $(\mathrm{P}=0.28)$.

It might also be expected that those who experience migraines with greater frequency are more likely to experience more than one severity type of attack. The results, however, showed no significant relationship between attack frequency and the number of types of attacks experienced $(\mathrm{P}=0.40)$.

Sex differences in the prevalence of migraine are well known and have been observed in previous studies (2). Celentano et al (9) investigated sex differences in the experience of headache symptoms and found that women were more likely to report disability with their most recent headache. However, the results of the present study did not indicate this $(\mathrm{P}=0.26)$.

Population-based studies in the United States, Canada, England and Sweden (10-14) have shown that many migraine sufferers either have never been diagnosed by a physician or have stopped seeing physicians about their migraine. Lipton and co-workers (11) reported that severe migraine-related disability is more common among those who have been diagnosed by physicians. The present 
TABLE 3

Average number of past $\mathbf{1 0}$ migraine attacks that were severely, moderately or somewhat limiting*

\begin{tabular}{lcccc}
\hline Level of debilitation of & AVERAGE NUMBER OF PAST 10 ATTACKS (SD) \\
past 10 attacks & $\begin{array}{c}\text { Severe }+ \text { moderate }+ \\
\text { somewhat }(\mathbf{n = 1 8 1 )}\end{array}$ & $\begin{array}{c}\text { Severe }+ \text { moderate } \\
(\mathbf{n = 3 2}\end{array}$ & $\begin{array}{c}\text { Severe + somewhat } \\
(\mathbf{n = 1 9 )}\end{array}$ & $\begin{array}{c}\text { Moderate }+ \text { somewhat } \\
(\mathbf{n = 3 4 )}\end{array}$ \\
\hline Severe & $3.5(2.6)$ & $6.4(2.6)$ & $5.1(3.5)$ & - \\
Moderate & $4.0(2.4)$ & $3.6(2.6)$ & - & $5.2(3.1)$ \\
Somewhat & $2.5(2.6)$ & - & $4.9(3.5)$ & $4.8(3.1)$ \\
\hline
\end{tabular}

${ }^{*}$ Data from those who ever experienced migraine attacks of two or more levels of debilitation and were able to answer the question adequately regarding their past 10 migraines

study showed similar results. Of those diagnosed by a doctor, $90 \%$ had experienced severely debilitating attacks; of those never diagnosed by a doctor, only $72 \%$ had experienced severely debilitating attacks. Those who had been diagnosed by doctors were more likely to have experienced attacks at all three levels of severity $(\mathrm{P}=0.04)$.

To assess how regularly they experience variability, sufferers were asked how many of their past 10 migraine attacks were severely limiting, moderately limiting and only somewhat limiting. This question is problematic in that some respondents with infrequent attacks or with a recent onset of attacks have not experienced 10 attacks, while other respondents have difficulties with recall or mental arithmetic. It was found, though, that $85 \%$ of respondents were able to provide an answer that totalled 10 , a percentage that seems reasonable considering that only $86 \%$ of Canadians are able to perform simple numerical operations such as addition or subtraction (15). Of those able to answer that question adequately, 79\% reported that at least two of their past 10 migraine headaches were of different levels of severity. This was more likely to be so among those who had experienced attacks at all three levels of severity $(91 \%)$ than among those who had only experienced two levels of

\section{REFERENCES}

1. Headache Classification Committee of the International Headache Society. Classification and diagnostic criteria for headache disorders, cranial neuralgias and facial pain. Cephalalgia 1988;8(Suppl 7):1-96.

2. Pryse-Phillips W, Findlay H, Tugwell P, Edmeads J, Murray TJ, Nelson RF. A Canadian population survey on the clinical, epidemiologic and societal impact of migraine and tension-type headache. Can J Neurol Sci 1992;19:333-9.

3. Rasmussen BK, Jensen R, Schroll M, Olesen J. Interrelations between migraine and tension-type headache in the general population. Arch Neurol 1992;49:914-8.

4. Bates D, Blau JN, Campbell MJ, et al. Migraine Management Guidelines. United Kingdom. London: Synergy Medical Education, 1993.

5. Optimum treatment of acute migraine and the place in therapy of sumatriptan. Drugs Ther Perspect 1993;1:1-4. (Edit)

6. Stewart WF, Schecter A, Lipton RB. Migraine heterogeneity: Disability, pain intensity, and attack frequency and duration. Neurology 1994;44(Suppl 4):S24-39.

7. Goadsby PJ. Diagnosis and optimum treatment of migraine. CNS Drugs 1994; 1:245-53.

8. Dahlsgaard-Nielsen T, Engberg-Pedersen H, Holm HE. Clinical and attacks (74\%). Table 3 shows, for each group of sufferers who had experienced two or more levels of attacks, the average number of the past 10 attacks that were severely, moderately or only somewhat debilitating. Thus, many migraine sufferers frequently experience attacks of varying severity and debility.

\section{DISCUSSION}

The results of our study give strong objective support to the clinical impression that most migraine sufferers frequently experience attacks of varying severity and debility. Further population-based research is needed to confirm these findings.

There are therapeutic implications. Recent guidelines have recommended different treatments for migraine, depending on the severity of the attack $(4,5)$. Because the issue of intrapatient variability in attack severity has only recently been emphasized, it is not surprising that up to $53 \%$ of sufferers who consult physicians and who experience two or more levels of attack severity, are still treated only with simple analgesics $(4,5,10)$ - inadequate for the more severe attacks. Appropriate therapy of migraine includes recognizing this variability and providing enough treatment options to relieve all of the patient's attacks.

statistical investigations of the epidemiology of migraine:

An investigation of the onset age and its relation to sex, adrenarche, menarche and the menstrual cycle in migraine patients, and of the menarche age, sex distribution and frequency of migraine. Dan Med Bull 1970;17:138-48.

9. Celentano DD, Linet MS, Stewart WF. Gender differences in the experience of headache. Soc Sci Med 1990;30:1289-95.

10. Edmeads J, Findlay H, Tugwell P, Pryse-Phillips W, Nelson RF, Murray TJ. Impact of migraine and tension-type headache on life-style, consulting behaviour, and medication use: A Canadian population survey. Can J Neurol Sci 1993;20:131-7.

11. Lipton RB, Stewart WF, Celentano DD, Reed ML. Undiagnosed migraine headaches: A comparison of symptom-based and reported physician diagnosis. Arch Intern Med 1992;152:1273-8.

12. Stewart WF, Lipton RB. Migraine headache: Epidemiology and health care utilization. Cephalalgia 1993;13(Suppl 12):41-6.

13. Green JE. Migraine abroad: A survey of migraine in England 1975-1976. Headache 1977;17:67-8.

14. Ekbom K, Ahlborg B, Schele R. Prevalence of migraine and cluster headache in Swedish men of 18. Headache 1978;18:9-19.

15. Statistics Canada. Survey of Literacy Skills Used in Daily Activities: Numeracy Skills. Ottawa: Statistics Canada, 1989 


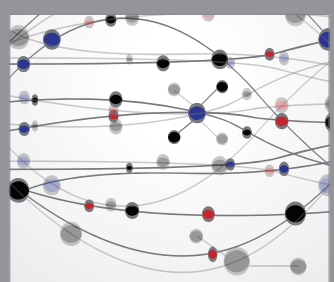

The Scientific World Journal
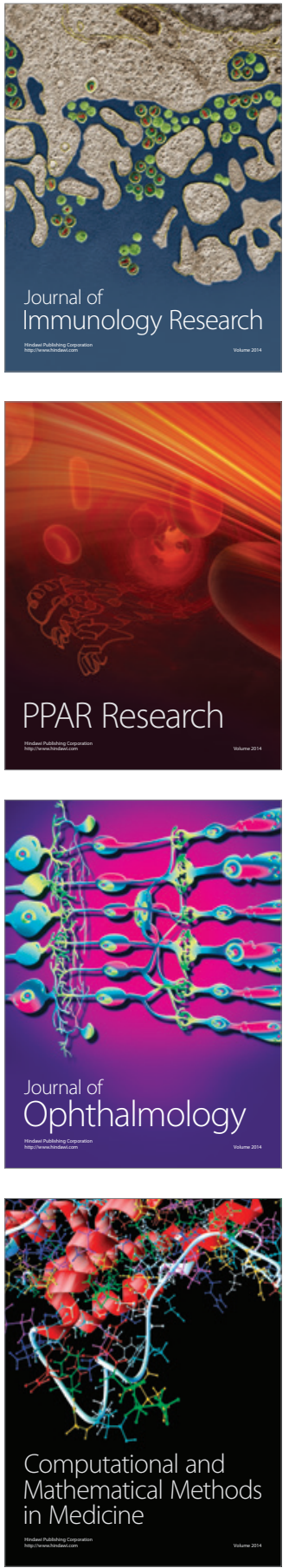

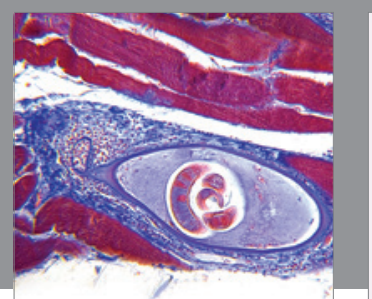

Gastroenterology Research and Practice

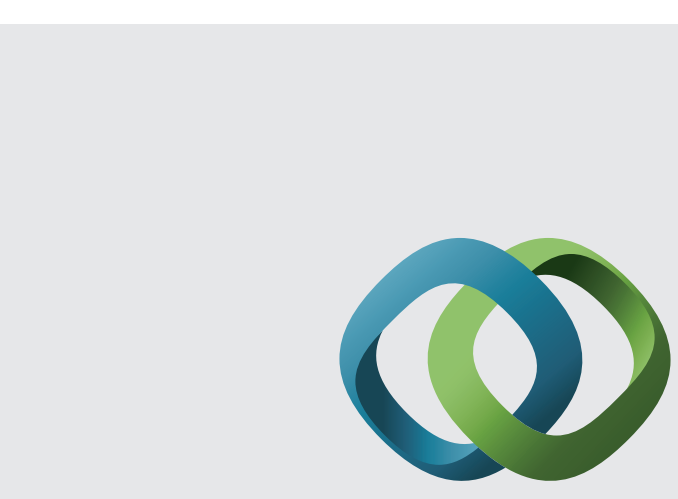

\section{Hindawi}

Submit your manuscripts at

http://www.hindawi.com
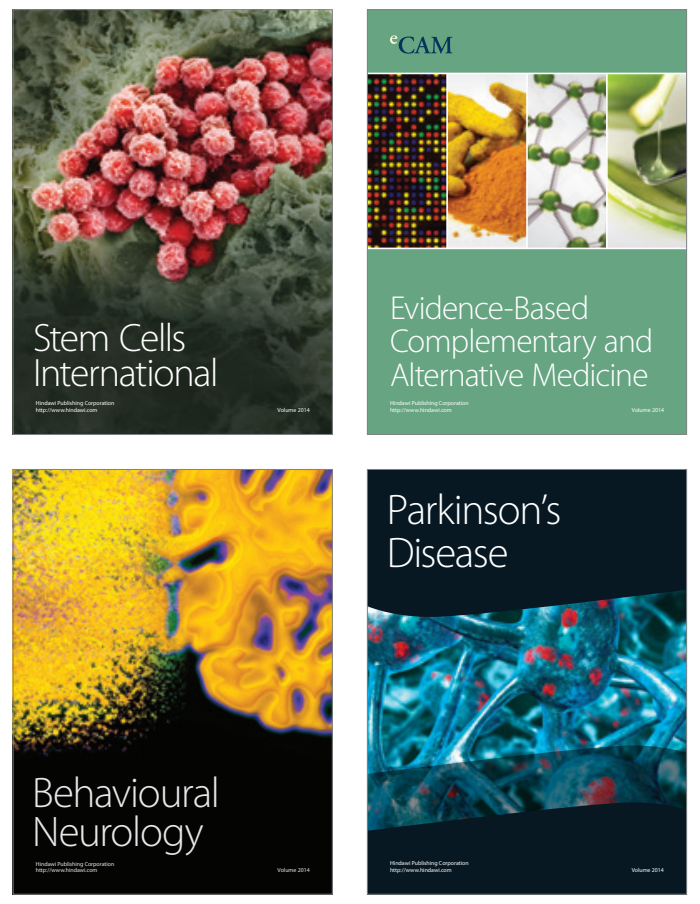
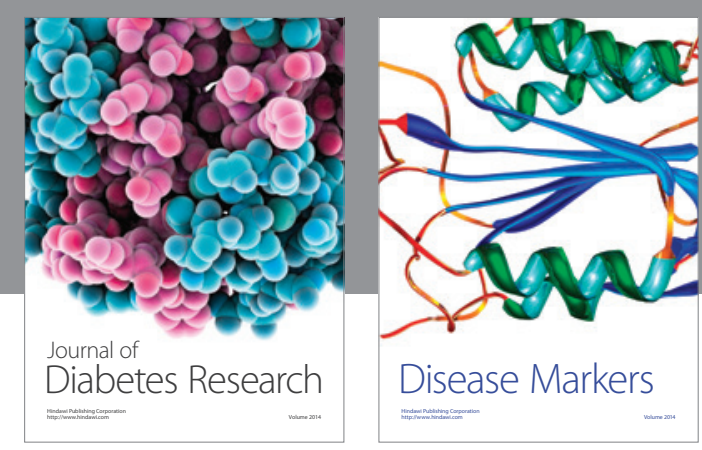

Disease Markers
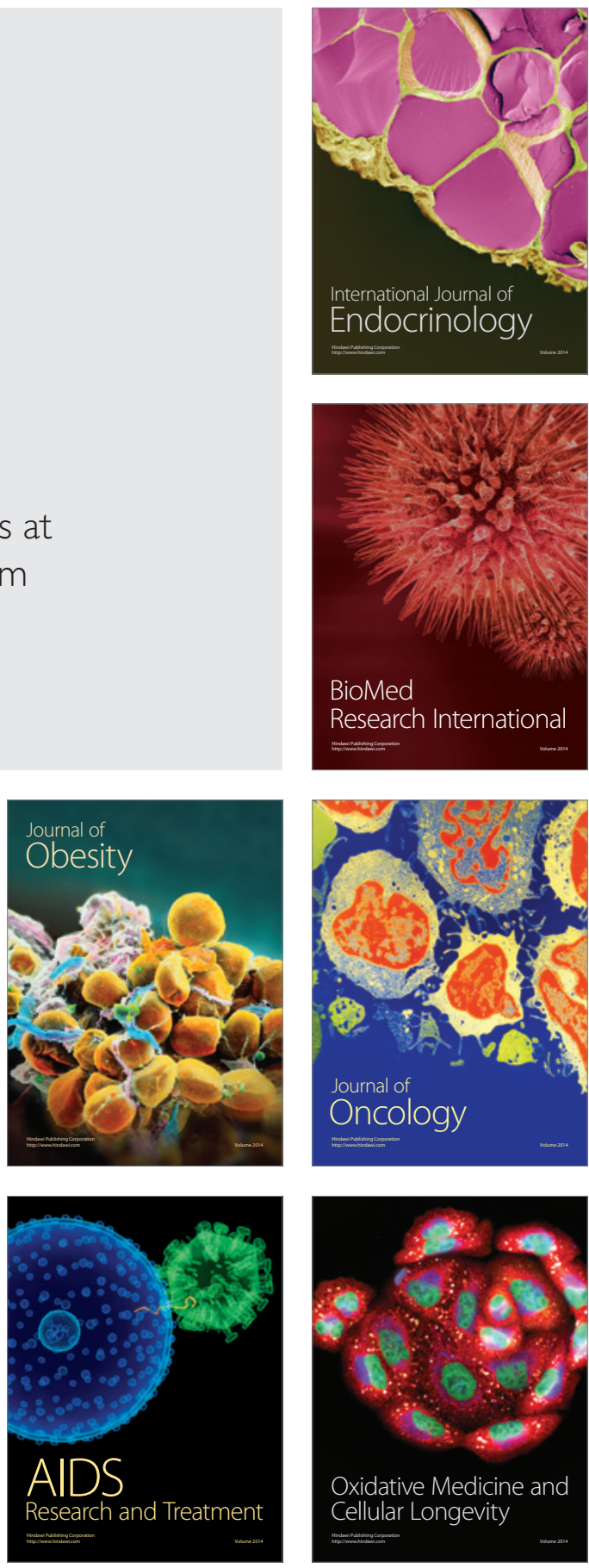